\title{
Erratum to: What is the Difference in Morphologic Features of the Thoracic Pedicle Between Patients With Adolescent Idiopathic Scoliosis and Healthy Subjects? A CT-based Case-control Study
}

\author{
Bo Gao MD, Wenjie Gao MD, Chong Chen MD, Qinghua Wang MM, \\ Shaochun Lin MM, Caixia Xu PhD, Dongsheng Huang MD, Peiqiang Su MD
}

Published online: 5 September 2017

(C) The Association of Bone and Joint Surgeons( 2017

\section{Erratum to: Clin Orthop Relat Res \\ DOI 10.1007/s11999-017-5448-9}

In the published paper, "What is the Difference in Morphologic Features of the Thoracic Pedicle Between Patients With Adolescent Idiopathic Scoliosis and Healthy Subjects? A CT-based Case-control Study" some errors can be found.

In the Methods section of the Abstract, the $\mathrm{p}$ value comparing patient height is incorrect. The $\mathrm{p}$ value should be " $p>0.05$ " not " $p<0.001$ ".

The online version of the original article can be found under doi:10. 1007/s11999-017-5448-9.

All ICMJE Conflict of Interest Forms for authors and Clinical Orthopaedics and Related Research ${ }^{\mathbb{B}}$ editors and board members are on file with the publication and can be viewed on request.

B. Gao, D. Huang

Department of Orthopaedics, Sun Yat-sen Memorial Hospital of Sun Yat-sen University, Guangzhou, China

W. Gao, Q. Wang, P. Su (ه)

Department of Orthopedics, The First Affiliated Hospital of Sun Yat-sen University, \#58 Zhongshan Road II, Guangzhou 510080, Guangdong, China

e-mail: supq@mail.sysu.edu.cn

W. Gao

Department of Spine Surgery, Xi'an Honghui Hospital, Xi'an Jiaotong University, Xi'an, China

C. Chen

Department of Orthopaedic Surgery, Peking Union Medical College Hospital, Peking Union Medical College and Chinese

Academy of Medical Sciences, Beijing, China
In Table 1, the $\mathrm{p}$ value for both the height and age demographics should be "p $>0.05$ ", not " $p<0.001$ ". The corrected Table 1 is provided here. 
Table 1. Demographic data of the patients and control subjects

\begin{tabular}{llll}
\hline Demographic & Patients with adolescent idiopathic scoliosis & Control subjects & P value \\
\hline Age (years) & $15 \pm 2.6$; range, 12-18 & $15 \pm 2.6 ;$ range, 12-18 & p $>0.05$ \\
Height $(\mathrm{cm})$ & $154 \pm 9$ & $155 \pm 10$ & $\mathrm{p}>0.05$ \\
Cobb's angle $\left({ }^{\circ}\right)$ & $53 \pm 13$; range, $40-96$ & Not available & - \\
Number of pedicles & 1322 & 1396 & - \\
\hline
\end{tabular}

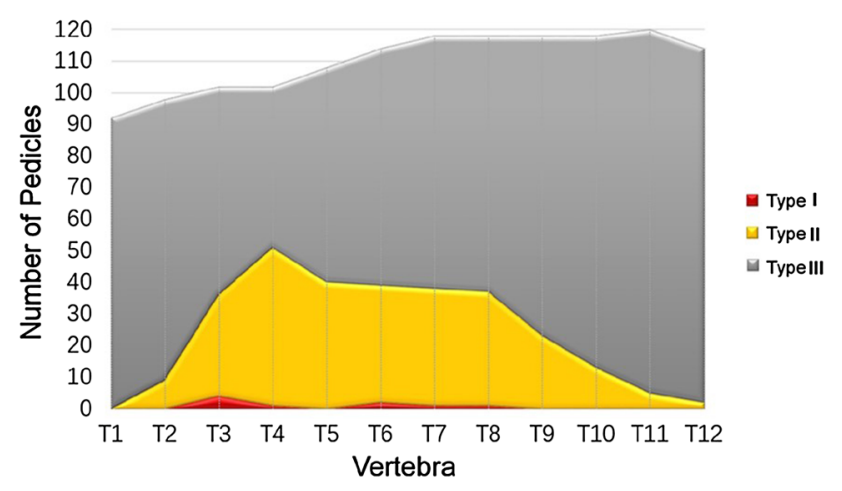

Fig. 4 The distribution of pedicles, defined as Types I through III, in each thoracic vertebra of the adolescent idiopathic scoliosis spine is shown.
In the Results section, Figure 4 is incorrect as published. The color red should represent Type I and the color grey should represent Type III. The corrected Figure 4 is provided here.

The authors apologize for the errors. 